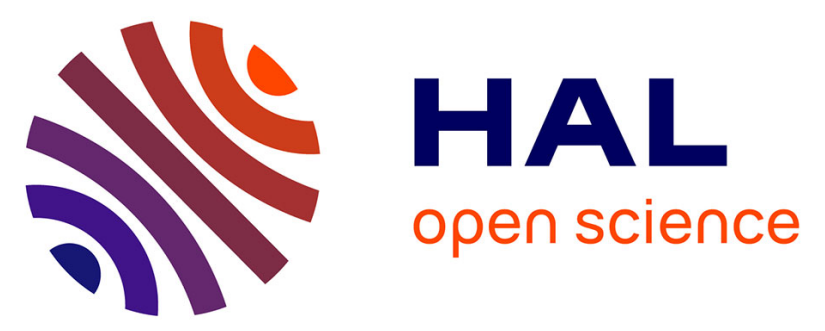

\title{
Investigating Unusual Organic Functional Groups to Engineer the Surface Chemistry of Mesoporous Silica to Tune CO 2 -Surface Interactions
}

Emily Bloch, Eric Besson, Séverine Queyroy, Richard Llewellyn, Stéphane Gastaldi, Philip L. Llewellyn

\section{To cite this version:}

Emily Bloch, Eric Besson, Séverine Queyroy, Richard Llewellyn, Stéphane Gastaldi, et al.. Investigating Unusual Organic Functional Groups to Engineer the Surface Chemistry of Mesoporous Silica to Tune CO 2 -Surface Interactions. ACS Applied Materials \& Interfaces, 2017, 9 (16), pp.14490 14496. 10.1021/acsami.7b00901 . hal-01524626

\section{HAL Id: hal-01524626 \\ https://hal-amu.archives-ouvertes.fr/hal-01524626}

Submitted on 3 May 2018

HAL is a multi-disciplinary open access archive for the deposit and dissemination of scientific research documents, whether they are published or not. The documents may come from teaching and research institutions in France or abroad, or from public or private research centers.
L'archive ouverte pluridisciplinaire HAL, est destinée au dépôt et à la diffusion de documents scientifiques de niveau recherche, publiés ou non, émanant des établissements d'enseignement et de recherche français ou étrangers, des laboratoires publics ou privés. 


\section{Investigating Unusual Organic Functional Groups to}

\section{Engineer the Surface Chemistry of Mesoporous}

\section{Silica to Tune $\mathrm{CO}_{2}$-Surface Interactions}

Emily Bloch ${ }^{\dagger}$, Eric Besson ${ }^{\S}$, Séverine Queyroy ${ }^{\S}$, Richard Llewellyn ${ }^{\S}$, Stéphane Gastaldi ${ }^{\S}$, Philip L. Llewellyn ${ }^{\dot{*} *}$

$\dagger$ Aix Marseille Univ, CNRS, MADIREL, Marseille, France

$\S$ Aix Marseille Univ, CNRS, ICR, Marseille, France

KEYWORDS: Carbon dioxide, functionalized mesoporous silica, microcalorimetry, in silico design, SBA-15

\section{ABSTRACT}

As the search for functionalized materials for $\mathrm{CO}_{2}$ capture continues, the role of theoretical chemistry is becoming more and more central. In this work, a strategy is proposed where ab initio calculations are compared and validated by adsorption microcalorimetry experiments for a series of, so far unexplored, functionalized SBA-15 silicas with different spacers (aryl, alkyl) and 
terminal functions $\left(\mathrm{N}_{3}, \mathrm{NO}_{2}\right)$. This validation then permitted to propose the use of a nitro-indole surface functionality. After synthesis of such a material the predictions were confirmed by experiment. This confirms that it is possible to fine tune $\mathrm{CO}_{2}$-functional interactions at energies much lower than those observed with amine species.

\section{INTRODUCTION}

The separation step in any chemical process can represent over $50 \%$ of the operational expenditure and separations, in general, represent $10-15 \%$ of the world energy use. Adsorption based separation processes such as Pressure Swing Adsorption ${ }^{1}$ can provide an interesting alternative to other techniques in terms of energy use, environmental impact, simplicity and overall cost. Indeed research is active in the use of adsorbents with the search for materials with improved properties in terms of uptake (working capacity) and selectivity for example. ${ }^{2}$ Increases in selectivity can be obtained by adjusting the pore size to increase the segregation between molecules of different sizes, known as molecular sieving. ${ }^{3}$ One can adapt the shape of the pores in order to allow for optimal packing and thus induce entropic effects to aid selectivity. ${ }^{4}$ One can equally fine-tune the chemistry of the adsorbent surface in order to induce stronger attractions for a target species thus increasing thermodynamic selectivity. ${ }^{5}$

Examples of the above effects can be found for the zeolite family of materials. As a first example, the compensation cations in the LTA zeolite structure can be found at the pore entrances and thus by changing the cation, the entrance size can be modified and this can lead to adsorbents which are highly selective to small molecules such as water. ${ }^{6}$ An example of an entropic separation can be found for para-xylene recovery using BaX zeolites in the Eluxyl 
process. ${ }^{7}$ Shape selectivity can also be observed with the ITQ-12 zeolite which is selective towards propane with respect to propene. ${ }^{8}$ In terms of chemistry, the use of lithium cations greatly improves the selectivity of zeolite $\mathrm{X}$ towards carbon dioxide. ${ }^{9}$

In terms of possibilities to vary the chemistry of adsorbents, the family of metal-organic frameworks (MOFs) is unprecedented with possibilities to vary either the metal modes, organic linkers to form different structures. ${ }^{10}$ It is additionally possible to graft organic functional groups to these nodes and linkers as well as incorporate cations or other species into the porous structure. One example is that of the UiO-66 family in which it is possible to vary the organic functions on the terephthalate linker. ${ }^{11}$ Additionally, computational methods have been used as tools to screen for the most optimal organic functional groups for carbon dioxide capture. ${ }^{12}$ The most interesting material in terms of chemistry has then be synthesized and experimentally verified for $\mathrm{CO}_{2}$ capture from nitrogen. ${ }^{13}$

The use of computational chemistry is extremely useful in such cases. Indeed, with over five thousand MOF structures and an almost infinite range of possibilities to functionalize the materials with organic moieties, a strategy based on computational screening is highly desirable. Furthermore, the creativity of organic synthesis chemists is huge and the range of functions that have been tested with adsorbent materials has been relatively limited. There is thus an opportunity to develop a strategy to explore a wide range of organic functions that could be of interest for a specific application in gas adsorption and separation.

Indeed, computational screening is well adapted as it is far less expensive, polluting and time consuming than the equivalent experimental studies involving synthesis and testing. The major drawback is the choice of the right computational parameters in order to account as best as possible for the effects to be screened for, without compromising on computer calculation rate. 
As a starting point, it is of importance to concentrate on the organic functions themselves. From a synthesis standpoint one can simply anchor the functions on a relatively neutral support to compare solely on the effect of the function. To this end, ordered mesoporous silica is an ideal candidate adsorbent support with SBA-15 being of particular interest owing to its large porosity, its high surface area and its easy functionalisation. ${ }^{14}$ As an initial test molecule to screen for, carbon dioxide is topical with a current focus in carbon capture and storage. In addition, from a computational point of view, $\mathrm{CO}_{2}$ is relatively simple to model. This rather simple $\mathrm{CO}_{2}$ case study, but with rather complex organic functions, will act as a springboard to highlight the usefulness of the strategy proposed and show the possibilities of further development to more complex problems.

There are a number of screening criteria that one can consider. ${ }^{15-16}$ Screening criteria can be based on uptake, or working capacity. Another criteria can be in terms of kinetic or thermodynamic selectivity. In the present study, we have chosen to screen the material in terms of energy. Indeed the interaction of any species with an adsorbent material will have a direct effect on the uptake rate and the difference in interactions for two different species will influence the selectivity. Finally the strength of interaction will equally affect other process parameters such as regenerability and column heat management. All of these points suggest that the interaction strength is a key point that can be used as a screening parameter.

To measure the interaction strength, one can calculate the isosteric enthalpies of adsorption from isotherms measured at different temperatures. ${ }^{17}$ A second approach is to directly measure the enthalpies of adsorption using microcalorimetry. ${ }^{18}$ These experimental enthalpies of adsorption can be compared to energies calculated using either ab initio or GCMC type calculations, thus allowing a validation of the computational approach. 
The aim of this article is thus to highlight the development of a strategy to develop materials with optimal organic functions for a given target molecule in a gas adsorption separation/storage type scenario. One of the criteria used in this work is to avoid overly strong interactions such as the chemisorption type interacts that are observed with amine functions and carbon dioxide where various species can be formed including carbamate, carbamic acid, and bidentate carbonate. ${ }^{19}$ The formation of such strongly bound species can be problematic in terms of regeneration. Therefore in this study, species leading to physisorption type interactions with $\mathrm{CO}_{2}$ have been privileged. Such interactions are both simpler to model and would lead to materials more suitable for adsorptive based separation processes. In this respect, we have chosen $-\mathrm{NO}_{2}$ and $-\mathrm{N}_{3}$ functions which are relatively stable, have permanent moments and whose adsorption properties have not yet been explored.

The strategy proposed in this work thus consists of firstly the synthesis of a series of materials in which organic linker and function have systematically been varied. In a second step adsorption microcalorimetry has been performed on these materials and a rationalization of the results has been carried out. At the same time in silico calculations have been made based on the functions synthesized and these results are compared to experiment. These calculations have suggested the use of further moieties with slightly stronger interactions for $\mathrm{CO}_{2}$ and one of these materials has been prepared. The confirmation of the increased interaction by microcalorimetry experiments permits such an in silico design strategy to be validated. This leads to conclusions and perspectives concerning the applicability of this approach to far more challenging systems.

\section{EXPERIMENTAL}




\section{Materials synthesis}

The organic-inorganic hybrid nanostructured silicas were prepared following the sol-gel process in the presence of a structure-directing agent and an alkyl(triethoxysilane). The syntheses of the trialkoxysilane precursors as well as their characterizations are fully described in the supporting information (SI). In a typical material synthesis, pluronic P-123 (2 g) in deionized water $(65 \mathrm{~mL})$ and $12 \mathrm{M}$ hydrochloric acid solution $(10 \mathrm{~mL})$ were stirred for $3 \mathrm{~h}$ at $40{ }^{\circ} \mathrm{C}$. Tetraethoxysilane (7.66 g, $36.85 \mathrm{mmol})$ and a trialkoxysilane precursor (4.09 mmol) were added. The mixture was stirred for $24 \mathrm{~h}$ at $40{ }^{\circ} \mathrm{C}$, then warmed without stirring at $100{ }^{\circ} \mathrm{C}$ for 2 days, filtrated, washed twice with water, once with ethanol and finally extracted with a Soxlhet apparatus (ethanol) for one day. The wet powder was filtrated, washed twice with ethanol, acetone and diethylether. After one night at $80{ }^{\circ} \mathrm{C}$ under vacuum, a powder was recovered. The characterizations of each silica are in SI. The structure of the organic moieties in the pore of the silicas and their loadings are given in Figure 1. The loading $1 / \mathrm{X}$ indicates the organic moieties/TEOS molar ratio determined after the characterization of the hybrid silicas.
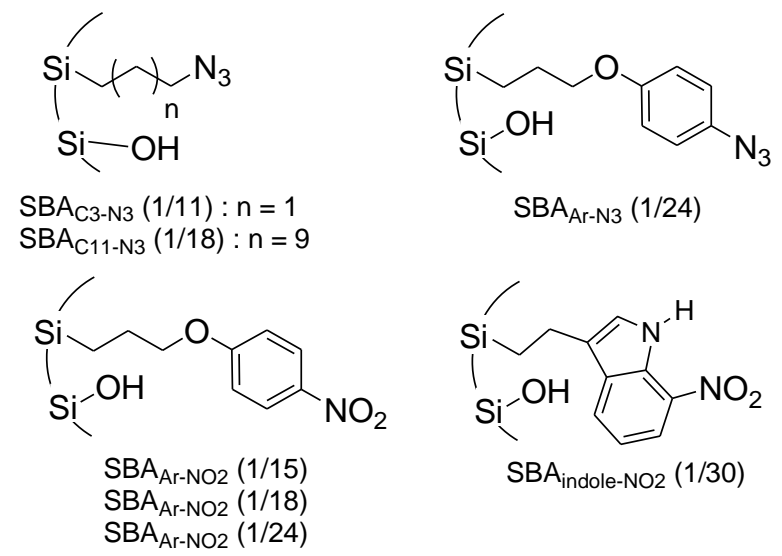

Figure 1. Structure of the silicas functionalized with an organic moiety in the pores. 


\section{Microcalorimetry}

Adsorption enthalpies were measured experimentally using a Tian-Calvet type microcalorimeter coupled with a home-made manometric gas dosing system. ${ }^{18}$ This apparatus allows the simultaneous measurement of the adsorption isotherm and the corresponding differential enthalpies. Gas is introduced into the system using a step-by-step method and each dose is allowed to stabilize in a reference volume before being brought into contact with the adsorbent located in the microcalorimeter. The introduction of the adsorbate to the sample is accompanied by an exothermic thermal signal, measured by the thermopiles of the microcalorimeter. The peak in the calorimetric signal is integrated over time to give the total energy released during this adsorption step. At low coverage the error in the signal can be estimated to around $\pm 0.2 \mathrm{~kJ} \mathrm{~mol}^{-1}$.

Two separate experiments were carried out at $30{ }^{\circ} \mathrm{C}$ using large $(0.6$ bar $)$ doses up 6 bar and small ( 0.1 bar) doses up to 1 bar respectively. Around $0.2 \mathrm{~g}$ of sample was used and was outgassed at $150{ }^{\circ} \mathrm{C}$ for 16 hours under secondary vacuum prior to each experiment. For each injection of gas, equilibrium was assumed to have been reached after 90 minutes. This was confirmed by the return of the calorimetric signal to its baseline $(<5 \mu \mathrm{W})$. The gas used for the adsorption was obtained from Air Liquide and was of N47 quality (99.997\% purity)

\section{Computer simulation}

All simulations have been performed with Gaussian 09 program. ${ }^{20}$ The starting structures were constructed with Agui 10.1. ${ }^{21}$ All systems contained one molecule of $\mathrm{CO}_{2}$ and one organic molecule of generic formula : H3Si-linker-function. For all the systems, a full geometry optimization was performed in vacuo at the MP2/6-311+g(d,p) level, and a harmonic frequency 
analysis was followed to characterize the located stationary points as true minima. The basis set superposition error (BSSE) was removed from the calculation of the complexation energies using the counterpoise correction protocol implemented into Gaussian. ${ }^{22,23}$ For each system, several conformations (with different starting position of the $\mathrm{CO}_{2}$ molecule) were optimized, some of which lead to the same minimum.

\section{RESULTS AND DISCUSSION}

\section{Materials characterization}

Prior to the evaluation of the effect of organic functionalization on $\mathrm{CO}_{2}$ adsorption, the prepared hybrid nanostructured silicas were fully characterized by nitrogen physisorption at $77 \mathrm{~K}$, thermogravimetric analysis, XRD and ${ }^{13} \mathrm{C}$ and ${ }^{29} \mathrm{Si}$ NMR spectroscopies. This characterization allows several materials parameters to be determined which are shown in Table 1. In general terms it would seem that as the loading of the function in the material increases, then the BET area decreases. It would equally seem that the BET area equally decreases when a longer linker unit is used. However, caution must be taken with such conclusions concerning BET area as the organic function density of the materials will change with the loading of organic material and any comparison per mass may not be rational and this point is further discussed below.

To further understand the role of the functionalization on the $\mathrm{CO}_{2}$ adsorption properties, calorimetry experiments were performed and different parameters were explored.

Effect of ligand loading 
An initial point that has been studied is the effect of the concentration of organic functions on the adsorption properties of carbon dioxide at $303 \mathrm{~K}$. In this respect, three samples were prepared with different loadings of the ' $\mathrm{NO}_{2}$ ' function with aryl ' $\mathrm{C}_{6} \mathrm{H}_{4}$ ' spacers. The number of ligands per $\mathrm{nm}^{2}$ almost doubles for each increment from 0.41 , to 0.75 and finally 1.6 for the $1 / 24,1 / 18$ and 1/15 samples respectively (Table 1).

Table 1. Characteristics of some of the materials prepared

\begin{tabular}{|c|c|c|c|c|c|}
\hline Material & Linker & Function & $A_{\text {BET }}\left(m^{2} \cdot g^{-1}\right)$ & $\begin{array}{l}\text { Function } \\
\text { per }-\mathrm{SiO}_{2}\end{array}$ & Function per $\mathbf{n m}^{2}$ \\
\hline $\mathrm{SBA}_{\mathrm{C} 3-\mathrm{N} 3}(1 / 11)$ & $\mathrm{C}_{3} \mathrm{H}_{6}$ & $\mathrm{~N}_{3}$ & 580 & $1 / 11$ & 1.4 \\
\hline $\mathrm{SBA}_{\mathrm{C} 11-\mathrm{N} 3}(1 / 18)$ & $\mathrm{C}_{11} \mathrm{H}_{22}$ & $\mathrm{~N}_{3}$ & 470 & $1 / 18$ & 1 \\
\hline $\mathrm{SBA}_{\mathrm{Ar}-\mathrm{N} 3}(1 / 24)$ & $\begin{array}{c}\mathrm{C}_{3} \mathrm{H}_{6} \mathrm{O}- \\
\mathrm{C}_{6} \mathrm{H}_{4}\end{array}$ & $\mathrm{~N}_{3}$ & $793(371)^{\mathrm{a}}$ & $1 / 24$ & 0.45 \\
\hline $\mathrm{SBA}_{\mathrm{Ar}-\mathrm{NO} 2}(1 / 15)$ & $\begin{array}{c}\mathrm{C}_{3} \mathrm{H}_{6} \mathrm{O}- \\
\mathrm{C}_{6} \mathrm{H}_{4}\end{array}$ & $\mathrm{NO}_{2}$ & 350 & $1 / 15$ & 1.6 \\
\hline $\mathrm{SBA}_{\mathrm{Ar}-\mathrm{NO} 2}(1 / 18)$ & $\begin{array}{c}\mathrm{C}_{3} \mathrm{H}_{6} \mathrm{O}- \\
\mathrm{C}_{6} \mathrm{H}_{4}\end{array}$ & $\mathrm{NO}_{2}$ & $632(270)^{\mathrm{a}}$ & $1 / 18$ & 0.75 \\
\hline $\mathrm{SBA}_{\mathrm{Ar}-\mathrm{NO} 2}(1 / 24)$ & $\begin{array}{c}\mathrm{C}_{3} \mathrm{H}_{6} \mathrm{O}- \\
\mathrm{C}_{6} \mathrm{H}_{4}\end{array}$ & $\mathrm{NO}_{2}$ & 900 & $1 / 24$ & 0.41 \\
\hline
\end{tabular}

Figure 2 shows the results obtained for these three samples for $\mathrm{CO}_{2}$ adsorption at $303 \mathrm{~K}$. Figure 2a shows the adsorption isotherms given as amount adsorbed per gram of solid. It would thus initially seem that the different loading of organic functions has no effect on uptake. However, as discussed above, one has to bear in mind that the silica and organic function have different densities and that this representation, per mass, does not compare equivalent volumes or 
equivalent quantities of 'silica' material. As a comparison per equivalent amount of silica is not straightforward, another approach that can be taken is to compare uptake per amount of accessible area using the results obtained from the BET analysis (Table 1). The isotherms replotted in terms of $\mathrm{CO}_{2}$ uptake per $\mathrm{m}^{2}$ of available (BET) surface is given in Figure $2 \mathrm{~b}$. It is clear from this plot that the more functions per surface, the higher uptake as would be expected, and that the overlap observed in Figure 2a is fortuitous. To summarize, as expected and at a first glance, the amounts adsorbed are proportional to the number of organic functions per $\mathrm{nm}^{2}$.
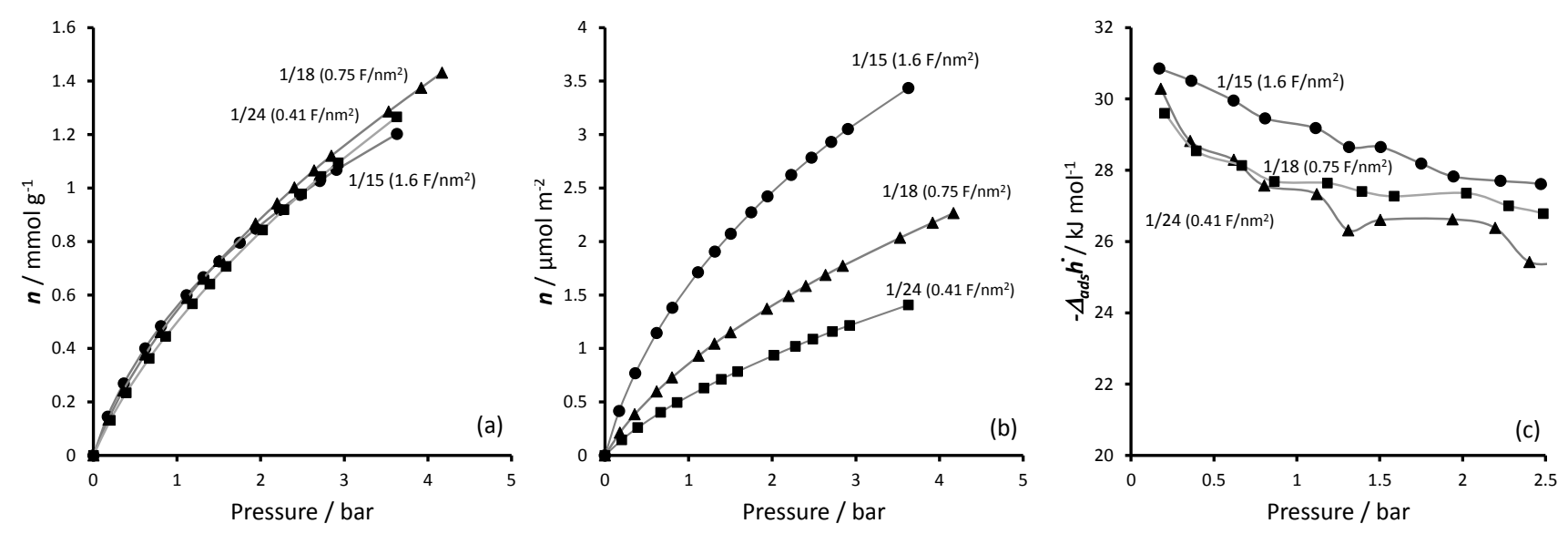

Figure 2. $\mathrm{CO}_{2}$ adsorption at $303 \mathrm{~K}$ on the series of ' $\mathrm{Ar}-\mathrm{NO}_{2}$ ' samples with different loadings of the function. (a) uptakes per gram of material, (b) uptakes per surface and (c) enthalpies of adsorption.

The isotherms show that comparing materials solely in terms of uptake is not a simple task. Comparing the adsorption enthalpies may be a way forward. In this respect, the energies of adsorption obtained with $\mathrm{CO}_{2}$ at $303 \mathrm{~K}$ are shown in Figure 2c. In this comparison, the materials with the lower concentration of functions show similar adsorption energies, and this could be expected if we consider that the $\mathrm{CO}_{2}$ interacts with each function. However slightly higher 
energies are measured with the sample with the highest density of organic functions per $\mathrm{nm}^{2}$, which may suggest cooperative effects between neighboring functions.

\section{Effect of linker and terminal function}

In choosing a terminal organic functional group to integrate into a material, one can attempt to separate the effect of the linker (or spacer) with that of the function. Indeed, the use of a linker with an aryl group will provide electrons which will affect the polarity of the function. Furthermore, the length of the linker may equally affect the chemistry of the organic functional group as well as the geometry. With this in mind, three linkers have been used with the same function (-N $\mathrm{N}_{3}$. These linkers include a $\mathrm{C}_{3}$ alkyl chain, a $\mathrm{C}_{11}$ alkyl chain and an aryl spacer. The results for $\mathrm{CO}_{2}$ adsorption at $303 \mathrm{~K}$ are shown in Figure 3.
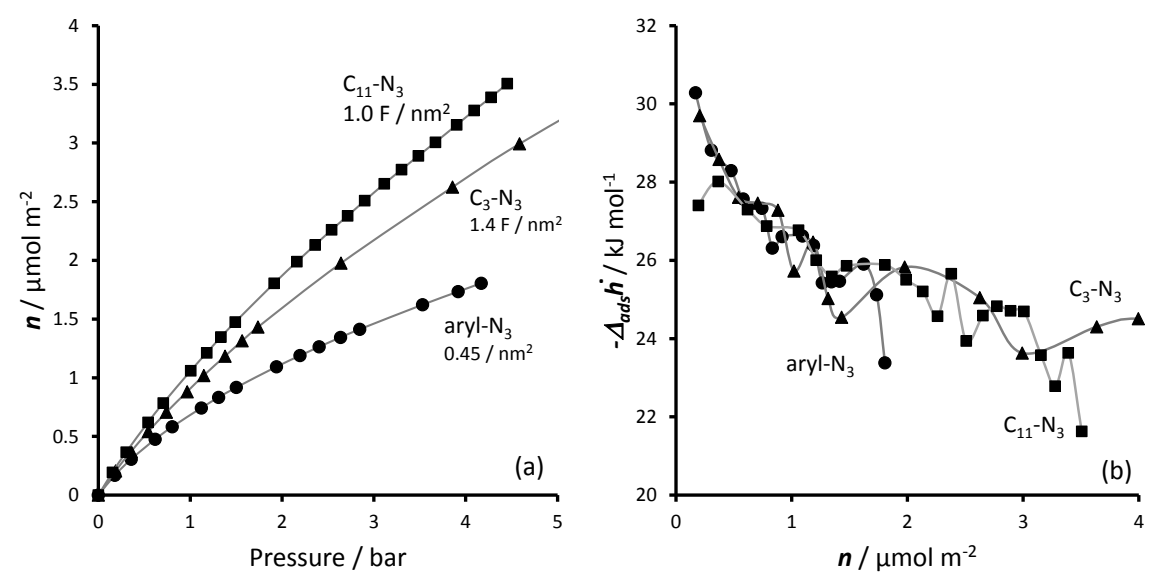

Figure 3. $\mathrm{CO}_{2}$ adsorption on materials with $-\mathrm{N}_{3}$ functions and various linkers : alkyl $\mathrm{C}_{3}$, alkyl $\mathrm{C}_{11}$, aryl. (a) uptakes per surface area and (b) enthalpies of adsorption.

The amount of $\mathrm{CO}_{2}$ adsorbed per unit surface, Figure 3a, seems to show an inverse trend with respect to the BET area (Table 1) and there seems to be no trend with respect to the number of organic functions per $\mathrm{nm}^{2}$. Indeed, in terms of enthalpy of adsorption, there equally seems to be no significant difference in energies with $\mathrm{CO}_{2}$ uptake. These results seem to suggest that the 
linker has little effect on the $\mathrm{CO}_{2}$ uptake in the particular cases chosen here. However, in other studies it has been shown that the inclusion of aryl groups or the position of the function in a chain can affect gas uptake. ${ }^{24}$ To compare the effect of the organic functional group present $\left(\mathrm{N}_{3}\right.$ versus $\mathrm{NO}_{2}$ ) on the $\mathrm{CO}_{2}$ adsorption properties, the same linker was used and the results are shown in Figure 4. In, this comparison, there are approximately the same functions per unit surface rendering the comparison slightly easier. There seems to be a greater uptake and slightly higher enthalpy of adsorption for $\mathrm{CO}_{2}$ with the $\mathrm{N}_{3}$ moiety with respect to the $\mathrm{NO}_{2}$ moiety. However any differences are small.
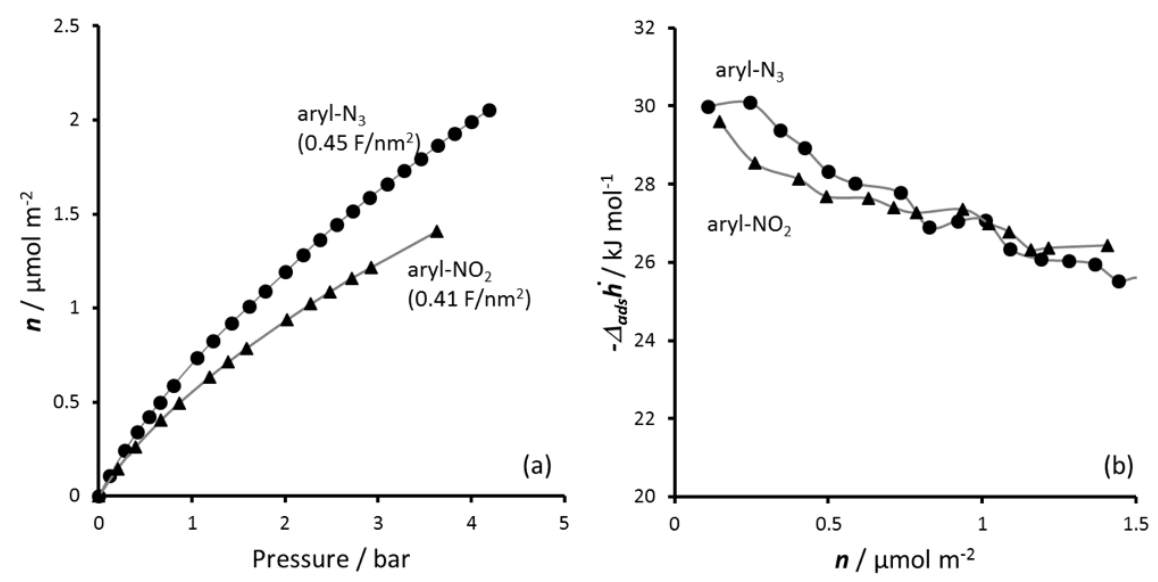

Figure 4. $\mathrm{CO}_{2}$ adsorption on materials with the same linker and different functions: $-\mathrm{N}_{3}$ and $\mathrm{NO}_{2}$. (a) uptakes per surface and (b) enthalpies of adsorption.

\section{Effect of passivation}

From the above results several questions arise. The first of these pertains to the fact that the silica based materials that have been prepared contain a significant quantity of hydroxyl groups. It can thus be difficult to separate the effect of the organic functional group on the $\mathrm{CO}_{2}$ adsorption with respect to the effect of surface hydroxyls. With this in mind, some of the samples 
were passivated with $\mathrm{Me}_{3} \mathrm{SiCl}$. Table 1 shows that the passivation led to a decrease in surface area by a factor 2 . The comparison of samples before and after passivation is given in Figure 5 .

Figure 5 highlights that the passivation has the same effect whatever the function present in the material. Indeed as can be expected, passivation leads to a decrease in surface area which translates to a decrease in $\mathrm{CO}_{2}$ uptake (SI).
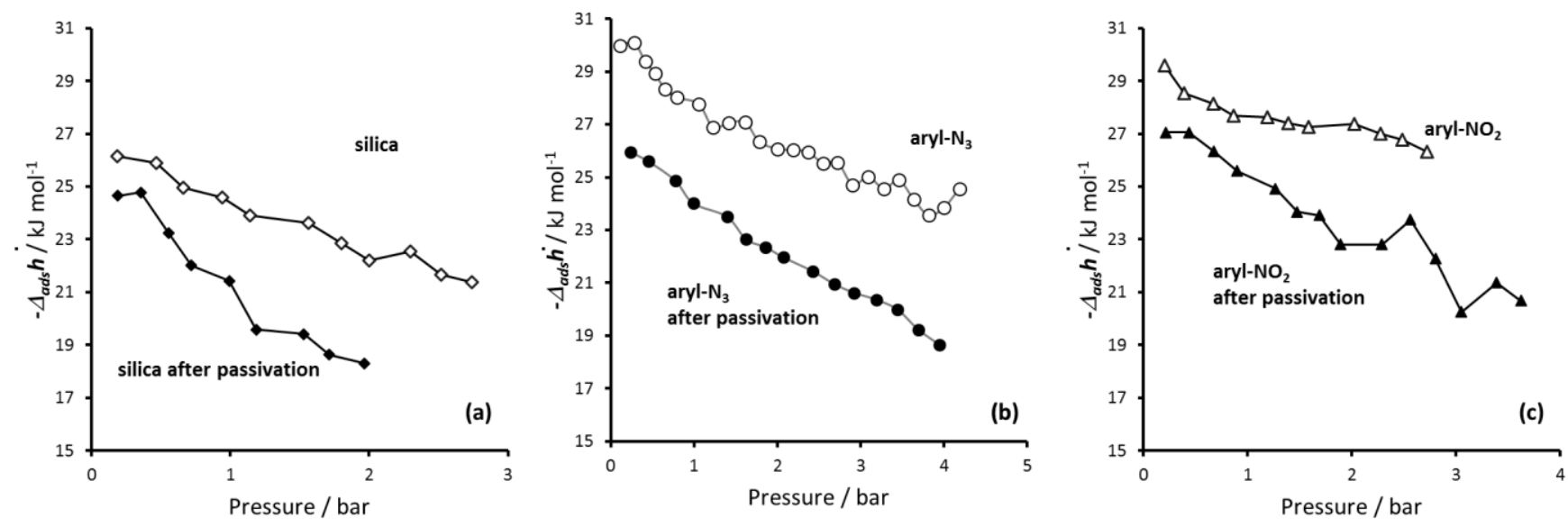

Figure 5. $\mathrm{CO}_{2}$ adsorption enthalpies on (a) silica, (b) aryl- $\mathrm{N}_{3}$ and (c) aryl- $\mathrm{NO}_{2}$ materials before and after passivation.

Furthermore, the passivation neutralizes interactions with $-\mathrm{OH}$ groups and this translates to a decrease in adsorption energy which depends on the organic functional group. Indeed this decrease is more noticeable in the case of the $-\mathrm{N}_{3}$ function $\left(4 \mathrm{~kJ} \mathrm{~mol}^{-1}\right.$, Figure $\left.5 \mathrm{~b}\right)$ than with the $\mathrm{NO}_{2}$ function $\left(2.5 \mathrm{~kJ} \mathrm{~mol}^{-1}\right.$, Figure $\left.5 \mathrm{c}\right)$. Inversely, this suggests that the $\mathrm{CO}_{2}$ would interact more strongly with the $-\mathrm{NO}_{2}$ alone than with the $-\mathrm{N}_{3}$ group alone. Nevertheless, this section highlights that the energies that we measure are most probably the result of a synergetic combination of $\mathrm{CO}_{2}$ interactions with both the organic functional group and surface hydroxyls, and which could equally be resultant of cooperative effects. 
To further aim to understand the effect of linker and terminal function on the $\mathrm{CO}_{2}$ interactions, $\mathrm{CO}_{2}$ adsorption was equally performed on the pure silica material which was then equally subjected to a passivation treatment. The energies of adsorption are also shown in Figure 5a and equally evidence a slight decrease in interaction energy $\left( \pm 1 \mathrm{~kJ} \mathrm{~mol}^{-1}\right)$, again related to loss of the possibility of $\mathrm{CO}_{2}$ interaction with surface $-\mathrm{OH}$ groups.

\section{Molecular modelling of the interactions in play}

To further understand and predict organic functional groups for a given probe molecule, $a b$ initio calculations were performed. Nevertheless, as we have partially seen above, the adsorption of $\mathrm{CO}_{2}$ depends on many criteria: the geometry of the material, the loading of the organic functions included in the material, the affinity of these organic functions for the gas, etc...

The part due only to the nature of the organic function and linker can be estimated in silico by computing the complexation energy between the functions and the gas. It is then possible to compare the enthalpies of adsorption at low loading with the calculations of the complexation energy of one molecule of $\mathrm{CO}_{2}$ and one organic functional group, obtained with quantum mechanical simulations. This would be the first step towards an in silico screening of potential functions for gas physisorption.

In order to compute reliable complexation energies, Second order Møller-Plesset simulations with $6-311+\mathrm{g}(\mathrm{d}, \mathrm{p})$ basis set were performed. We expect that this level of theory would take properly into account correlation's effects. BSSE corrected complexations energies for each complex $\left(\mathrm{CO}_{2}+\right.$ molecule $)$ are reported in Table 2 . 
Table 2. BSSE corrected complexations energies between $\mathrm{CO}_{2}$ and different molecules.

\begin{tabular}{|c|c|c|}
\hline Molecule & Conformation & $\mathrm{E}_{\text {complexation }}\left(\mathrm{kJ} \mathrm{mol}^{-1}\right)$ \\
\hline $\mathrm{C}_{3} \mathrm{~N}_{3}$ & $\mathrm{a}$ & -9.6 \\
\hline $\mathrm{C}_{3} \mathrm{~N}_{3}$ & $\mathrm{~b}$ & -5.4 \\
\hline $\mathrm{C}_{3} \mathrm{NO}_{2}$ & $\mathrm{a}$ & -9.6 \\
\hline $\mathrm{C}_{3} \mathrm{NO}_{2}$ & $\mathrm{~b}$ & -9.6 \\
\hline $\operatorname{Ar} N_{3}$ & $\mathrm{a}$ & -7.2 \\
\hline $\operatorname{Ar} N_{3}$ & $\mathrm{~b}$ & -9.6 \\
\hline $\operatorname{Ar} \mathrm{NO}_{2}$ & $\mathrm{a}$ & -8.4 \\
\hline $\operatorname{Ar} \mathrm{NO}_{2}$ & $\mathrm{~b}$ & -8.4 \\
\hline Indole- $\mathbf{N}_{3}$ & & -13.4 \\
\hline Indole-NO & & -12.6 \\
\hline
\end{tabular}

For a given complex, several conformations (shown in Figure 6 and in the SI) corresponding to energy minima could be found and explains the multiple entries in the table. If we take into account only the lowest energy minima (statistically more representative), these results indicate 
that $\mathrm{N}_{3}$ and $\mathrm{NO}_{2}$ functions have similar complexation energies. The aryl and alkyl linkers also behave similarly. These results are confirmed experimentally above.
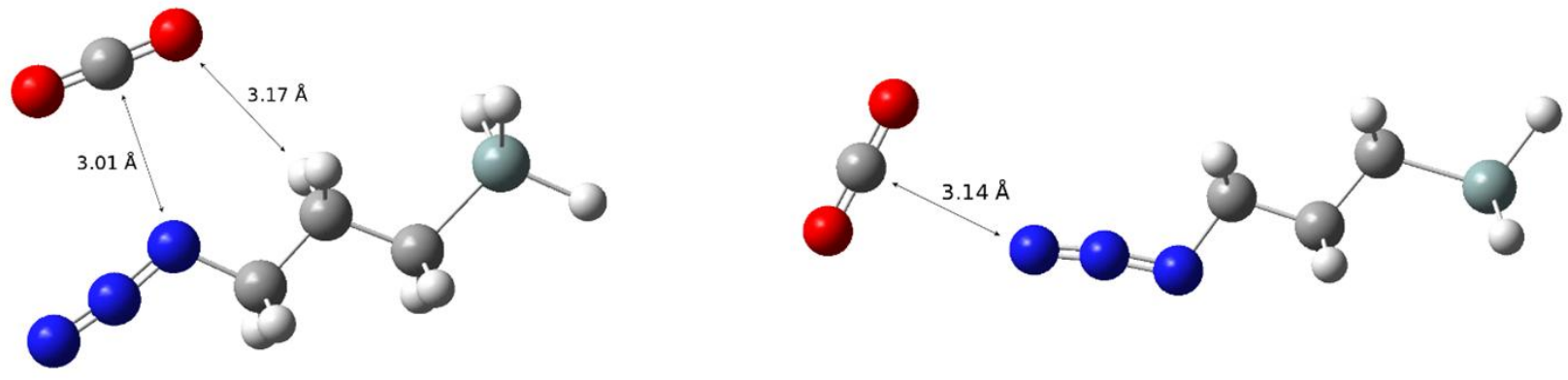

Figure 6. Two conformations of $\mathrm{CO}_{2}-\mathrm{C}_{3} \mathrm{~N}_{3}$ complex

Hydrogen bonding with the silanol groups on the material surfaces has also been investigated. For the $\mathrm{C}_{3} \mathrm{~N}_{3}$ molecule, the complexation energy is $-12.6 \mathrm{~kJ} \mathrm{~mol}^{-1}$ if one $\mathrm{SiOH}$ is added to the molecule $\left(\mathrm{OH}-\mathrm{SiH}_{2}-\mathrm{O}-\mathrm{SiH}_{2}\right.$-linker-function). This further interaction represents a gain of around $3 \mathrm{~kJ} \mathrm{~mol}^{-1}$. This value compares well with the decrease in enthalpy measured experimentally for the materials obtained before and after passivation (Figure 5). Thus this in silico approach seems to provide an interesting correspondence with experiment.

However, in order to induce stronger interactions with the $\mathrm{CO}_{2}$ molecule, further linkers and conformations were explored. The effect of the $\mathrm{SiOH}$ suggests the use of an indole linker which may induce an enhanced complexation energy due to a secondary interaction via hydrogen bonding between the $\mathrm{NH}$ of the indole and $\mathrm{CO}_{2}$ (see Table 2). To simplify the syntheses, a nitro group was preferred rather than an azido and the corresponding nitro-indole material was prepared from commercially available 7-nitro-indole as depicted in scheme 1. 


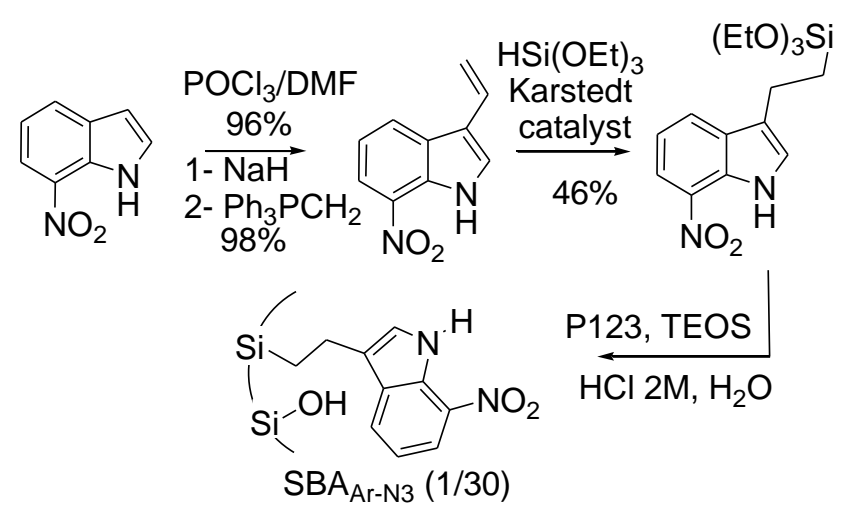

Scheme 1. Synthesis scheme of SBA-15 with aryl-indole function.
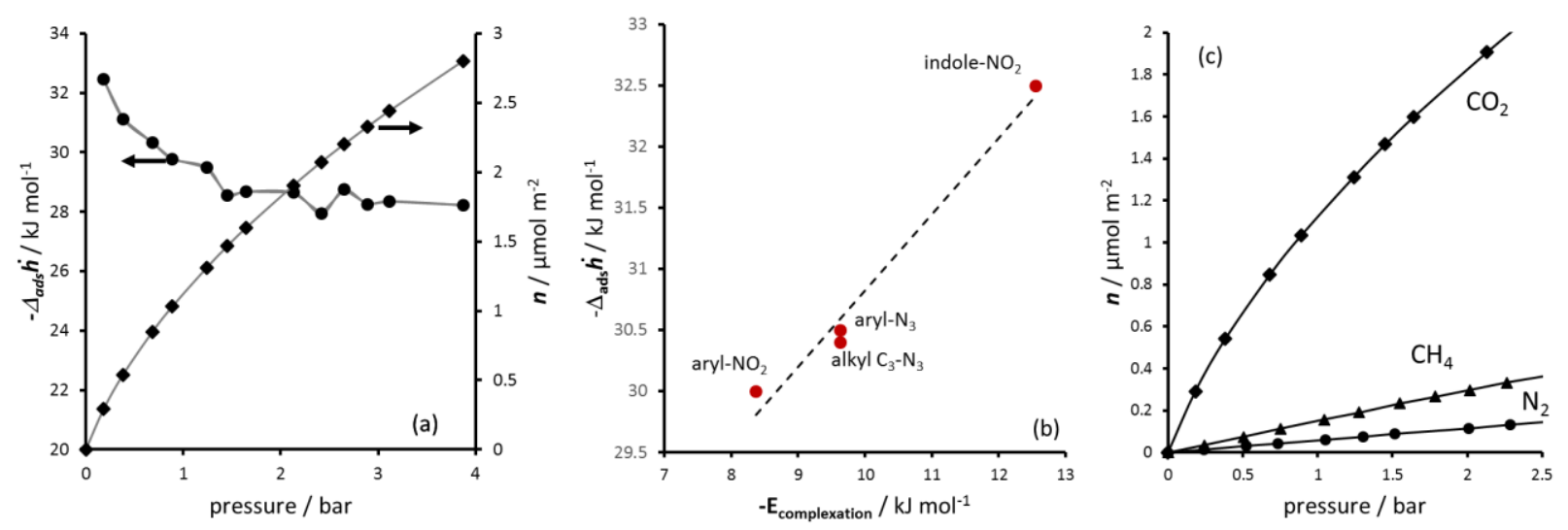

Figure 7. (a) Adsorption of $\mathrm{CO}_{2}$ at $303 \mathrm{~K}$ on mesoporous silica functionalized with 7-nitroindole functions, (b) relationship between measured initial enthalpies of adsorption and calculated average complexation energies, and (c) comparison of $\mathrm{CO}_{2} \mathrm{CH}_{4}$ and $\mathrm{N}_{2}$ uptakes.

The $\mathrm{CO}_{2}$ adsorption measurement was carried out as shown in Figure 7a. This result indeed shows a slightly enhanced adsorption energy and this allows a plot of measured adsorption 
energy at low coverage as a function of predicted complexation energy to be constructed (Figure $7 b)$.

The plot in Figure $7 \mathrm{~b}$ further suggests that a general correlation can be made between the in silico screening and experimental results which is encouraging for future research in terms of material design for a given probe molecule. This also means that the simplifications implied by our simulation model (only one chain, only one $\mathrm{CO}_{2}$, no surface, etc...) have a negligible impact on the selection of the best organic moieties. This sample may show interest with respect to $\mathrm{CO}_{2}$ capture for $\mathrm{N}_{2}$ or $\mathrm{CH}_{4}$ as it can be seen from Figure $7 \mathrm{c}$ that the uptakes of these latter gases are quite negligible with respect to $\mathrm{CO}_{2}$. This is confirmed as the adsorption energies at low coverage are equally much lower for $\mathrm{N}_{2}\left(17 \mathrm{~kJ} \mathrm{~mol}^{-1}\right)$ and $\mathrm{CH}_{4}\left(15 \mathrm{~kJ} \mathrm{~mol}^{-1}\right)$ than for $\mathrm{CO}_{2}$. Finally, IAST calculations ${ }^{25}$ of selectivity lead to a value of 35 for a $15 \% \mathrm{CO}_{2} / 85 \% \mathrm{~N}_{2}$ mixture at 1 bar, representative of flue gas, and 15 for a $50 \% \mathrm{CO}_{2} / 50 \% \mathrm{CH}_{4}$ mixture. These encouraging results of enthalpy and selectivity suggest that it can be possible to fine tune materials chemistry with the use of less standard organic functions. This is especially the case when would like to move away from the quite, maybe overly, strong interactions that can be found when using amine functionalization. Further, the overall aim of this study was to develop a strategy of materials design, using a quite simple case study. This can clearly be adapted to other gas and vapor targets more appropriate for such hybrid materials. As such the use of in silico screening with more complex organic functions may be a way forward in studying more challenging problems such as propane/propene separations and the recovery of toxic vapors for example. Indeed, where subtle differences in gas mixture or where toxic molecules are involved, a computer aided screening strategy is optimal for materials design. 


\section{CONCLUSIONS}

This work has highlighted that computer simulations can be used to model the interactions of carbon dioxide with organic functional groups that can be incorporated into mesoporous silica. We suggest that the use of microcalorimetry may be a more pertinent data parameter than uptake in the characterization of materials where only subtle differences are required or that in instances where effects such as available surface area or functional group density may also play roles.

Microcalorimetry can be used to both characterize the effect of function, linker and surface and compares well with the in silico modeling. Interestingly the computer modeling can further be used to follow the effect of surface hydroxyls in the proximity of the organic functions studied. This experimental validation of the in silico modeling thus opens an approach to screen many other organic functions in order to find materials with optimal features for gas capture.

As a perspective, this screening may permit to explore more complex organic functions and linkers to lead to composite interactions where several anchor points can be used to interact with more intricate target molecules. Indeed, this exploration can be expanded to cover little or unknown organic functions to be attached that can be synthesized and incorporated using one pot materials synthesis as described above. This computer aided approach can be used to treat this problem from the materials perspective where one could screen one given organic function's potentiality to interact with a range of target molecules. Overall, this work is the first step in a strategy to use in silico screening for the optimization of materials design and synthesis. 


\title{
ASSOCIATED CONTENT
}

Supporting Information. Details of energy minima conformations, synthesis and characterization (NMR, SAXS, $\mathrm{N}_{2}$ adsorption and TGA) are given in the supporting information.

\author{
AUTHOR INFORMATION \\ *philip.1lewellyn@univ-amu.fr
}

\section{Author Contributions}

The manuscript was written through contributions of all authors. All authors have given approval to the final version of the manuscript. All authors contributed equally.

\section{REFERENCES}

1. Samanta, A.; Zhao, A.; Shimizu, G.K.H.; Sarkar, P.; Gupta, R., Post-Combustion $\mathrm{CO}_{2}$ Capture Using Solid Sorbents: A Review. Ind. Eng. Chem. Res., 2012, 51, 1438-1463.

2. Mersmann, A.; Fill, B.; Hartmann, R.; Maurer, S., The Potential of Energy Saving by Gas-Phase Adsorption Processes. Chem. Eng. Tech., 2000, 23, 937-944.

3. Caro, J.; Noack, M.; Kolsch, P.; Schafer, R. Zeolite Membranes - State of their Development and Perspective. Micro. Meso. Mat., 2000, 38, 3-24. 
4. Krishna, R.; Smit, B.; Calero, S. Entropy Effects during Sorption of Alkanes in Zeolites. Chem. Soc. Rev., 2002, 31, 185-194.

5. Sircar, S. Basic Research Needs for Design of Adsorptive Gas Separation Processes. Chem. Eng. Tech., 2006, 45, 5435-5448.

6. Cartigny, J.; Giermanskakahn, J; Delara, E.C. Frequency-Response Method in the Study of Methane Diffusion in 3 Cation Exchanged Zeolites-A. Zeolites, 1994, 14, 576-581.

7. Ash, G.; Barth, K.; Hotier, G.; Manl, L.; Renard, P. Eluxyl - A New Paraxylene Separation Process. Rev. Inst. Fr. Pét., 1994, 49, 541-549.

8. Barrett, P. A. ; Boix, T.; Puche, M; Olson, D. H.; Jordan E.; Koller, H.; Camblor, M. A. ITQ-12: A New Microporous Silica Polymorph Potentially Useful for Light Hydrocarbon Separations. Chem Commun, 2003, 7, 2114-2115.

9. Baksh, M. S. A.; Kikkinides, E. S.; Yang R. T. Lithium Type X Zeolite as a Superior Sorbent for Air Separation. Sep. Sci. Tech., 1992, 27, 277-294.

10. Zhou, H. C.; Kitagawa, S. Metal-Organic Frameworks (MOFs). Chem. Soc. Rev., 2014, $43,5415-5418$.

11. Bai, Y.; Dou, Y. B.; Xie, L.-H.; Rutledge, W.; Li, J.-R.; Zhou, H.-C. Zr-based MetalOrganic Frameworks: Design, Synthesis, Structure, and Applications. Chem. Soc. Rev., 2016, 45, 2327-2367.

12. Wu, D.; Yang, Q. Y.; Zhong, C. L.; Liu, D. H.; Huang, H. L.; Zhang, W. J.; Maurin, G. Revealing the Structure-Property Relationships of Metal-Organic Frameworks for $\mathrm{CO}_{2}$ Capture from Flue Gas. Langmuir, 2012, 28, 12094-12099.

13. Yang, Q. Y.; Vaesen, S.; Ragon, F.; Wiersum, A. D.; Wu, D.; Lago, A.; Devic, T.; Martineau, C.; Taulelle, F.; Llewellyn, P. L.; Jobic, H.; Zhong, C. L.; Serre, C.; De Weireld, G.; Maurin, G. A Water Stable Metal-Organic Framework with Optimal Features for $\mathrm{CO}_{2}$ Capture. Angew. Chem. Int. Ed., 2013, 52, 10316-10320. 
14. Vinu, A.; Hossain, K. Z.; Ariga, K. Recent Advances in Functionalization of Mesoporous Silica. J. Nanosci. Nanotech., 2005, 5, 347-371.

15. Wiersum, A. D.; Chang, J.-S.; Serre, C.; Llewellyn, P. L. An Adsorbent Performance Indicator as a First Step Evaluation of Novel Sorbents for Gas Separations: Application to Metal-Organic Frameworks. Langmuir, 2013, 29, 3301-3309.

16. Rege, S. U.; Yang, R. T. A Simple Parameter for Selecting an Adsorbent for Gas Separation by Pressure Swing Adsorption. Sep. Sci. Technol., 2001, 36, 3355-3365.

17. Rouquerol, J.; Rouquerol, F.; Llewellyn, P.; Maurin, G.; Sing K. S. W. Adsorption by Powders and Porous Solids, Principles, Methodology and Applications, Second Edition (2014), Academic Press, Oxford (G.B.), 646 pages.

18. Llewellyn, P. L.; Maurin, G. Gas Adsorption Microcalorimetry and Modelling to Characterise Zeolites and Related Materials. C. R. Chimie, 2005, 8, 283-302.

19. Knöfel, C.; Martin, C.; Hornebecq, V.; Llewellyn, P. L., Study of Carbon Dioxide Adsorption on Mesoporous Aminopropylsilane-Functionalized Silica and Titania Combining Microcalorimetry and in Situ Infrared Spectroscopy. J. Phys. Chem. C, 2009, 113, 21726-21734.

20. Frisch, M. J.; Trucks, G. W.; Schlegel, H. B.; Scuseria, G. E.; Robb, M. A.; Cheeseman, J. R.; Scalmani, G.; Barone, V.; Mennucci, B.; Petersson, G. A.; Nakatsuji, H.; Caricato, M.; Li, X.; Hratchian, H. P.; Izmaylov, A. F.; Bloino, J.; Zheng, G.; Sonnenberg, J. L.; Hada, M.; Ehara, M.; Toyota, K.; Fukuda, R.; Hasegawa, J.; Ishida, M.; Nakajima, T.; Honda, Y.; Kitao, O.; Nakai, H.; Vreven, T.; Montgomery, Jr., J. A.; Peralta, J. E.; Ogliaro, F.; Bearpark, M.; Heyd, J. J.; Brothers, E.; Kudin, K. N.; Staroverov, V. N.; Keith, T.; Kobayashi, R.; Normand, J.; Raghavachari, K.; Rendell, A.; Burant, J. C.; Iyengar, S. S.; Tomasi, J.; Cossi, M.; Rega, N.; Millam, J. M.; Klene, M.; Knox, J. E.; Cross, J. B.; Bakken, V.; Adamo, C.; Jaramillo, J.; Gomperts, R.; Stratmann, R. E.; Yazyev, O.; Austin, A. J.; Cammi, R.; Pomelli, C.; Ochterski, J. W.; Martin, R. L.; Morokuma, K.; Zakrzewski, V. G.; Voth, G. A.; Salvador, P.; Dannenberg, J. J.; 
Dapprich, S.; Daniels, A. D.; Farkas, O.; Foresman, J. B.; Ortiz, J. V.; Cioslowski, J.; Fox D. J., Gaussian 09, Revision D.01. Gaussian, Inc., Wallingford CT, 2013.

21. www.semichem.com

22. Boys, S. F.; Bernardi, F. Calculation of Small Molecular Interactions by Differences of Separate Total Energies - Some Procedures with Reduced Errors, Mol. Phys., 1970, 19, 553-566.

23. Simon, S.; Duran, M.; Dannenberg J. J., How Does Basis Set Superposition Error Change the Potential Surfaces for Hydrogen Bonded Dimers?. J. Chem. Phys., 1996, 105, 1102411031.

24. Zelenak, V.; Halamova, D.; Gaberova, L.; Bloch, E.; Llewellyn, P. Amine-Modified SBA-12 Mesoporous Silica for Carbon Dioxide Capture: Effect of Amine Basicity on Sorption Properties, Micro. Meso. Mat., 2008, 116, 358-364.

25. Myers, A. L.; Prausnitz, J. M., AIChE J., 1965, 11, 121-127. 